\title{
Planning in mathematics teaching - a varied, emotional process influenced by others
}

\author{
Helena Grundén
}

Linnaeus University and Dalarna University, Sweden

Planning is an essential part of teachers' work that has consequences for students' learning. However, previous research shows that what it means to plan vary. To explore the meaning of planning from teachers' point of view, and to open up for planning as a situated and emotional process, an interview study with Swedish mathematics teachers was conducted. In the analysis, the theoretical concepts, meaning, and emotions were used as analytical tools to fill the gap identified in the review of previous research about planning. Findings reveal planning as a varied process in which teachers draw on different resources. Actors other than teachers influence both how planning is done and the mathematics teaching that is planned for. Findings also reveal that feelings, such as joy, shame, and insufficiency, are present in the process of planning. These feelings sometimes have consequences for decisions teachers make about their mathematics teaching.
Article Details
LUMAT General Issue Vol 8 No 1 (2020), 67-88
Received 7 April 2020
Accepted 20 May 2020
Published 1 June 2020
Pages: 22
References: 29
Correspondence: hgn@du.se
https://doi.org/10.31129/
LUMAT.8.1.1326

Keywords: emotions, mathematics teaching, meaning, planning

\section{Introduction}

Teachers make decisions about their teaching that have consequences for students' possibilities to learn mathematics. In mathematics education research, there is an increasing interest in those decisions (Potari, Figueiras, Mosvold, Sakonidis, \& Skott, 2015) and there has been a shift of emphasis from research on teachers and their characteristics to an emphasis on acts of teaching (Skott, Mosvold, \& Sakonidis, 2018). Teaching, in turn, involves not only teachers' actions in the classroom, but also some parts of teachers' work outside the classrooms, including planning.

Planning differs both within and between cultures and between teachers (e.g., Roche, Clarke, Clarke, \& Sullivan, 2014), and one reason is to what extent curriculum materials influence and govern the teaching. Influence and government can, on the one hand, vary depending on how detailed the curriculum materials are. On the other, they can vary depending on how teachers interact with the materials. In Sweden, for example, teachers have, at least in theory, a high degree of freedom to plan their teaching (Utbildningsdepartementet, 2009), and the national curriculum does not provide detailed instructions. Despite differences, there is a common feature between descriptions that planning includes the choice of mathematical content and activities 
in relation to specific students. Attempts have been made to grasp this common feature in models and templates (e.g., Goméz, 2002). The rationale behind these models and templates can, for example, be to use them in teacher education or to support teachers (John, 2006). However, some studies show that teachers do not plan in line with the models and templates (e.g., Zazkis, Liljedahl, \& Sinclair, 2009), and one reason is according to Hargreaves (1998) that planning models take no account of, for example, emotions, which in turn might indicate that planning is more complex and inadequate to simplify and fit into a model where the complexity is getting lost. Emotions in mathematics education are emphasized by Evans (2001), which can support the importance of emotions also in the planning process.

Existing planning processes have been described in various ways, such as a psychological process (Clark \& Yinger, 1987), as curriculum implementation (Superfine, 2008), as interaction with curriculum materials (Remillard, 2005), or as a process where the choice of activities is emphasized (Roche et al., 2014; Superfine, 2008). Hence, there is a diversity in meaning when researchers talk about planning, and it seems reasonable to believe that planning also is understood in various ways on various levels in school organizations, for example, among teachers and school leaders.

Acknowledging planning as an essential part of teaching makes a lack of recognition of the diverse meanings of planning problematic, for example, in expectations of teachers, in discussions between teachers and school management, in teacher education, and in supporting material for teachers. Since teachers are the ones responsible for planning, their perspective on the meaning of planning may be particularly interesting, especially since results from an Australian study suggest that initiatives to support teachers in the planning process should start in what they already do (Sullivan, Clarke, Clarke, Gould, et al., 2012; Sullivan, Clarke, Clarke, Farrell, \& Gerrard, 2013). Hence, insights into mathematics teachers' own processes and meaning-making are essential.

This article aims to contribute with such insights by presenting results from an interview study exploring what I choose to understand as planning, i.e., an on-going process of considerations, decisions, and reflections about future teaching. In the preliminary analysis of the interviews, it turned out that feelings1 are a significant part of the meaning of planning, much in line with Alvesson and Karreman (2000) and

\footnotetext{
${ }^{1}$ In this article, emotions, and feelings are used interchangeably.
} 
Hargreaves (1998). Based on the interviews with six mathematics teachers, two questions will be answered in the article: What meaning do teachers ascribe to planning? And also, what emotional aspects emerge when teachers ascribe meaning to planning? The answers will open up for a discussion about the complex processes involved in planning and what we can learn from these processes concerning teachers' decisions and actions.

\section{Previous research on planning}

Most studies on planning in mathematics teaching focus on learning studies, lesson studies, or on teachers' mathematical knowledge in relation to planning. Few articles focus on planning as a recurring everyday activity, which is at the scope of this article, but the few found were of two kinds. In some of the articles, the intention seems to be prescriptive, i.e., by giving suggestions on how to do it, authors aim to improve/support/develop planning in mathematics planning (e.g., Gomez, 2002, Zazkis et al., 2009). Other articles focus on describing and understanding the process of planning in mathematics teaching through for example case studies in the USA (Superfine, 2009) and Spain (Muñoz-Catalán, Yánez, \& Rodríguez, 2010), and a larger study with focus groups and a survey made in Australia (e.g., Roche et al., 2014). Although the articles were different and could be sorted into prescriptive articles versus descriptive articles, three themes were spanning over them: models and templates, supporting, changing, and improving teachers' planning, everyday work.

Some studies acknowledge the social aspects of planning. However, "social" often means interactions with colleagues and social life in classrooms, which means that research about planning for mathematics teaching where "social" is seen in a wider sense seems to be missing. Consequently, the previous studies can contribute with insights into some aspects of planning, but address the complex processes of planning with a focus on meaning, methodological tools other than those used in previous studies about planning in mathematics teaching are necessary.

\subsection{Models and templates for planning}

Studies focusing on models and templates often build on linear ideas about planning where the models have much in common (John, 2006). In the models, planning is equated with choosing content, linking to curriculum, specifying learning objectives, 
goals, and teaching methods, choosing activities, and thinking of assessment (e.g., John, 2006). Models for planning are frequently used in teacher education, but practicing teachers rarely use them (Zazkis et al., 2009). Reasons for using models in teacher education include students need to learn how to plan rationally before being able to grasp the whole process. Reasons for wanting in-service teachers to use models can, for example, be a wish to control teachers (John, 2006). However, Hargreaves (1998) argues that models used for planning are flawed because they do not take emotional aspects into account.

Another critique on using linear models is that reflections and "the negotiated nature of learning" (John, 2006, p. 487) is getting lost, and that important factors that influence teachers' planning are omitted (Superfine, 2008). In line with this critique, alternative models for planning are described. An organic model that recognizes different kinds of decisions and the decision-making of experienced teachers has been developed by John (2006). In another alternative model, relations between curriculum, teachers' experiences, and teachers' conceptions are used to understand planning problems. This model is however used to understand the process of planning rather than to support teachers in the planning process (Superfine, 2008). In yet another model, which, although based on linear models, Gomez (2002) tried to include some social aspects that influence planning. In the model, planning is acknowledged as a social activity where teachers have to face both individual and social [on a classroom level] problems in collaboration with colleagues.

\subsection{Supporting, changing, and improving planning}

Advice on how to support, change, and improve teachers' planning is common in the research literature. For in-service teachers, collegial work and support from colleagues are important when developing planning skills (Muñoz-Catalán et al., 2010; Sullivan et al., 2013). For example, in Muñoz-Catalán et al. (2010), a novice teacher developed her flexibility in the planning process by working with more experienced colleagues.

Somewhat contradictory to the increased flexibility when planning that is described as desired by Muñoz-Catalán, some researchers suggest that support and improvement in the process of planning could be provided through specific templates or models (e.g., Gomez, 2002; Zazkis et al., 2009). Such suggestions seem to indicate a wish for more rigid planning. In addition to templates and models, curriculum materials, such as teacher guides, are produced and used to implement reforms and 
to support teachers in their planning process (Superfine, 2008), and for the support to be as effective as possible teacher guides should be clear and prescriptive (Smith \& Sendelbach, 1979 in Clark \& Yinger, 1987). Clear and prescriptive teacher guides include, for example, "summaries of the mathematical content, specific questions to ask students throughout a lesson, and examples of student errors" (Superfine, 2008, p. 12). However, Sullivan et al. (2012) conclude that "attempts to be overly prescriptive or to provide a 'teacher-proof' lesson will be counterproductive" (p. 702). Instead, they argue, education and developmental work that concerns planning should be based on processes that teachers already use.

Despite teachers' different processes, there are aspects identified as important for developing teachers' ability to plan. One such aspect is developing a "Plan B- ability" (Martin \& Mironchuk, 2010) to handle situations where plans are "challenged by the realities of classroom life" (p. 23). In an attempt to handle this unpredictability of teaching situations, Zazkis et al. (2009) suggest an activity, "lesson play," in which student teachers are encouraged to engage in planning and imagine potential interactions, different possibilities, and possible student responses. A lesson play focuses on a mathematical concept and takes difficulties or misconceptions that students often have into account. In the play, there is close attention to mathematical language and various forms of mathematical reasoning that might emerge.

Sullivan et al. (2012), Martin \& Mironchuk (2010), and Zazkis et al. (2009) all emphasize the importance of seeing planning as closely related to teachers' and students' everyday life.

\subsection{Everyday work of planning}

The everyday work of planning involves many simultaneous considerations, where aspects such as tacit knowledge and intuition, and conceptions of teaching and learning are of importance (Superfine, 2008). When planning, teachers often start with activities and nature of content rather than starting with objectives and goals (John, 2006), as emphasized in the models building on linear thinking.

A critical aspect of planning is working with curriculum materials (e.g., Remillard, 2005), and there are different views of how this is done. Teachers are sometimes described as curriculum implementers (Superfine, 2008), which indicates that there is a direct link between curriculum documents, teachers' plans, and what is enacted in classrooms. Another way of describing teachers' work with curriculum materials is "transforming curriculum ideas, captured in the form of mathematical tasks, lesson 
plans, and pedagogical recommendations into real classroom events" (Remillard, Herbel-Eisenmann, \& Lloyd, 2009, p. 1), which means that teachers interact with curriculum materials, and hence, both the material and the teacher influence what is planned (Remillard, 2005). In these interactions, formal curriculum, e.g., policy documents, textbooks, and teacher guides, are transformed into the planned curriculum, which in turn is transformed into the enacted curriculum in the meeting with the students (Remillard, 2005). The complexity of planning and the interaction with curriculum materials is also described by Sullivan et al. (2013), who states that teachers need to interpret the curriculum and match the interpretation with mathematical ideas and tasks. Hence, teachers need to extract mathematical ideas and anticipate the potential of tasks, which, according to Sullivan et al. (2013), is a challenge for the Australian teachers that participated in their study.

When planning, teachers are influenced, for example, by assessments they made (Sullivan et al., 2013); official documents; materials developed by themselves and their peers; and web-based curriculum materials (Clarke, Clarke, \& Sullivan, 2012). The context in which the planning is done is also of importance (e.g., Roche et al., 2014). Planning in the USA is often described as teachers taking given tasks from instructional material and based on those tasks plan implementation and assessment of the mathematical content. In Australia, teachers seem to exercise autonomy (Sullivan et al., 2013) and are expected to plan at the year and the unit level as well as at the level of the lesson (Sullivan et al., 2012). In contrast to, for example, Japan and China, unit and lesson plans are, to a large extent, personal and made to respond to the needs of particular students and individual teachers' styles (Roche et al., 2014). Teachers may draw on various resources such as national, state, and school-level curriculum documents when they plan. Other resources might be web-based material, commercial material, information about students provided by assessment, and colleagues.

\subsection{Conclusions from the literature review}

To summarize, in previous research, there is a common view that planning is an essential part of mathematics teaching. Planning is mainly described as an activity where teachers make different decisions about their teaching. However, the degree to which researchers see planning as a complex and situated process varies, but not even those who recognize the complexity and situatedness emphasize emotional aspects of planning. Hence, there seems to be a lack of research that, in line with 
recommendations from Hargreaves (1998), approach planning as an emotional practice. Roche et al. (2014) argue that traditions, expectations, and assumptions underlying teachers' planning are of importance for further research, and hence, exploring planning in mathematics teaching based on what meaning teachers ascribe to it is relevant. Besides, such focus opens up for insights into what the "social" and emotions mean in relation to planning. However, since there is a lack of research in the mathematics education field that acknowledges the complexity, the situatedness, and the emotional aspects of planning, there is, as mentioned in the above, a need to search for methodological tools other than those found in previous research.

\section{Theoretical concepts}

In this article, two essential theoretical concepts that are common in studies focusing on the wider social context of teachers' work will function as analytical tools: meaning and emotions. In the following sections, I present the understanding of these concepts that underpins this article.

\subsection{Meaning}

Meaning, in Cambridge Dictionary, stated as "what something represents or expresses" ("meaning," n.d.). According to Alvesson and Karreman (2000), meaning should be understood beyond what is stated in a glossary, namely as situated and produced in social practices, such as mathematics teaching, for example, when people talk. In their production of meaning, i.e., their meaning-making, people represent parts of the world in different ways, and those who listen interpret in turn what they hear. Hence, the meaning is made through an interplay between the one who produces what is said, what is said, and the one who interprets what is said (Fairclough, 2003). People make meaning in interactions with others, influenced by power, ideologies, and history (Cherryholmes, 1999). When people make meaning, there is a meeting between the individual dimension with previous experiences, the social dimension in relation with others, and the cultural dimension (Quennerstedt, Öhman, \& Öhman, 2011). Hence, meaning in this article is seen as consisting of both what Alvesson and Karreman (2000) calls durable meaning, including cultural and individual ideas, and what they call transient meaning that is situated and tightly connected to language use in interactions. The meaning that is produced includes, according to Alvesson and Karreman (2000), the ways people make sense of specific issues and also how they 
interpret, value, think, and feel about them. Based on this, meaning in this study implies teachers making sense of, interpreting, valuing, thinking, and feeling about planning in mathematics, which means that meaning includes emotional dimensions, and hence, this definition of meaning can contribute to describing planning as the emotional practice Hargreaves (1998) suggests.

\subsection{Emotions}

In this article, emotions are seen as significant in the process of meaning-making (Alvesson \& Karreman, 2000). Emotions are seen as both individual psychological phenomena and socio-cultural situated "cultural artefacts that convey socio-cultural messages" (Zembylas, 2007, p. 61) in line with what Zembylas calls the interactionist perspective. Expressions of emotion are seen as discursive, which means that what is possible to feel and say about feelings differs between discourses (Zembylas, 2005). However, in this study, the focus is not on discursive aspects, but on what emotions are expressed. Evans (2001) argues that it is possible to study emotions in all kinds of texts by looking for "indicators for the experiencing of emotions, such as verbal expressions of feeling, body language, emphasis or repetition of certain terms, and metaphors" (pp. 90-91), which means that it is possible to use texts, such as transcripts from interviews, to access the emotional parts of meaning-making.

\section{Method}

To explore the meaning of planning that emerge in teachers' stories, I needed to learn about their world, and a useful way to do this is interviewing (Qu \& Duman, 2011). To find participants for the interviews, eight mathematics teachers and seven principals were contacted. In the end, six teachers from five different schools agreed to participate. All of them were teaching mathematics as one of several subjects (which is common in Sweden), four of them taught mathematics and science in compulsory school year 7-9, and two of them were class teachers teaching almost all subjects in compulsory school year 1-3. They were all experienced mathematics teachers $(>10$ years of teaching).

When doing interviews, there is a risk that words of the interviewer and words of the interviewees have different meanings (Qu \& Dumay, 2011). Since previous studies indicate that there is no unambiguous way to talk about planning and this study aims to explore the meaning that teachers ascribe to the concept, I decided not to provide 
my definition or explanation of planning in contact with the teachers before and during the interviews.

Focusing on teaching in research implies challenges when it comes to grasping aspects of teaching not easily observable. This includes planning. In this study, I handled the challenges by giving each participant a notebook a few weeks before the interviews in which the teachers were asked to make notes, draw pictures, or add material that for them were related to planning. My intention with the notebooks was to study planning from teachers' perspectives. The teachers used the notebooks to prepare for the interview and brought the notebooks to the interview so that the notes reminded the teachers of previous thoughts. In that way, the notebooks served as stimuli during the interviews, which opened up for the conversation not only to touch on things the teachers came to think of in the interview situation but also what they thought and reflected on earlier. Hence, the design opened up for the possibility to grasp the durable as well as the transient meaning (Alvesson \& Karreman, 2000). Interviews lasted between 24 and 60 minutes and were recorded and transcribed. Since the aim was not to explore individual teachers' meaning, all the interviews were gathered in one transcript. For this article, quotations are translated from Swedish to English.

\section{Analysis}

Conducting interviews with notebooks as stimuli was one way of foregrounding teachers' experiences and meaning, and throughout the analysis, attempts were made to stay close to teachers' utterances. In order to grasp the complex process of planning, the analysis was made based on the idea that using language to express, reflect, and inform are ways of acting (Fairclough, 2003) and that semiosis is meaning-making as an element in social processes (Fairclough, 2016). This means that teachers in their utterances do semiotic actions that are involved in meaning-making about planning for mathematics teaching. According to Alvesson and Karreman (2000), meaning implies "a (collectivity of) subjects' way of relating to-making sense of, interpreting, valuing, thinking, and feeling about-a specific issue” (p. 1147). Thus, meaningmaking involves what teachers do, value, think, and feel, inspired by Alvesson and Karreman's (2000).

The analysis was made in three steps: 1) extraction of important passages in the transcript, 2) thematic analysis, and 3) focus on feelings. I the first step, the transcript was sieved through the abovementioned categories of do, i.e., semiotic actions about 
what teachers say they do when planning, and how planning is practically done; value and think, semiotic actions answering the questions "How do teachers value planning?" respectively "What do teachers think of planning?"; and feel semiotic actions where feelings are expressed. In this way, the parts of the material that concerned meaning about planning were deductively categorized for further thematic analysis (step 1 in figure 1 ).

The analysis so far involves getting familiar with the data, which is described as the first phase in a thematic analysis (Braun and Clarke, 2006), but also involves the extraction of passages in the transcript where meaning was ascribed to planning. Then all extracts were coded with respect to what each utterance was about; see Table 1 , for example.

Table 1. Examples from generating initial codes

\begin{tabular}{|l|l|}
\hline Data extract & Coded for \\
\hline I need to have them |the students] on my side & Relations \\
\hline $\begin{array}{l}\text { I asked them [the students]: What do we do } \\
\text { now? }\end{array}$ & Student participation \\
\hline
\end{tabular}

After that, extracts were "collected together within each code" (Braun \& Clarke, 2006, p. 89). The different codes were then sorted into sub-themes, for example, the codes: student participation, relations, different needs, and students' attitude, were sorted into the sub-theme "students"; and the codes: assessment, grade, and examination were sorted into the theme "assessment." At this stage, relations between codes and sub-themes were considered, and four main themes were formed: Mathematics and students, Resources, Work of planning, and Impact of others (step 2 in figure 1). These themes represent the core content of the meaning the teachers ascribe to planning. All teachers are represented within each theme, although not all teachers are represented within each code. For example, there are extracts from all teachers in the sub-code assessment in which five of the teachers talked directly about assessment, while the sixth teacher talked about grades.

In this article, there is a special interest in emotions as significant in the process of meaning-making. Hence, semiotic actions found in the first filtering of the transcript through the category feel were analyzed separately (step 3 in figure 1) based on the questions: What does the teacher feel something about? What feelings are explicitly expressed? What is a reasonable interpretation of implicitly expressed feelings? In table 2, examples from the analysis are shown. 
Table 2. Examples from analysis of emotional aspects

\begin{tabular}{|l|l|l|l|}
\hline Extract & $\begin{array}{l}\text { What are your } \\
\text { feelings about? }\end{array}$ & $\begin{array}{l}\text { What feelings are } \\
\text { explicitly expressed? }\end{array}$ & $\begin{array}{l}\text { Interpretation of } \\
\text { implicitly expressed } \\
\text { feelings? }\end{array}$ \\
\hline $\begin{array}{l}\text { "planning in } \\
\text { mathematics teaching } \\
\text { is really fun." }\end{array}$ & Planning & Joy & \\
\hline $\begin{array}{l}\text { "I am a little } \\
\text { embarrassed because } \\
\text { that [the teaching she } \\
\text { had planned for] is } \\
\text { not what I stand for." }\end{array}$ & $\begin{array}{l}\text { Teaching } \\
\text { Herself }\end{array}$ & Embarrassment & Shame \\
\hline
\end{tabular}

In the second example in the table, "I am a little embarrassed because that the teaching she had planned for] is not what I stand for," I interpret the combination of embarrassment and "is not what I stand for" as an implicitly expressed feeling of shame. Expressions of emotion go across all of the four themes and were expressed by all achers but one.

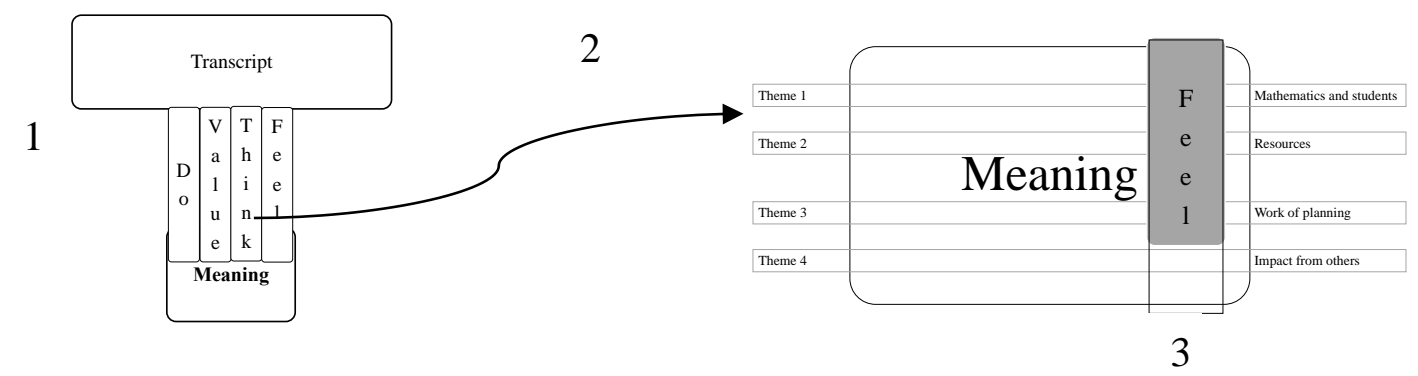

Figure 1. Overview of analysis 


\section{Results}

The results are presented in two sections. In the first, the meaning the teachers ascribed to planning is presented, and in the second, emotional aspects of meaning are presented.

\subsection{Meaning of planning}

In this section, the core content of the meaning the teachers ascribed to planning is presented. It is not the meaning each teacher expressed, but a synthesized meaning of planning to which all six teachers have contributed. The intention is not to give a picture of all teachers' meaning of planning, but to give insights into meaning some Swedish teachers ascribe to planning. The result is organized around the four themes Reflections on mathematics and students, Resources for planning, Work of planning, and Impact of others.

\section{Reflections on mathematics and students}

Despite no common view on what planning includes, there is a common feature: making decisions about the mathematical content in relation to specific students. These decisions are made for a longer period, such as a semester, or a lesson or a series of lessons. In relation to long-term planning, distributing the mathematical content over one semester or one school year is one example of such work. One teacher describes how this is done: "I make a plan for one semester based on the textbook." Even if planning is not based directly on a textbook, there are several examples in the interviews where headlines in the book (e.g., Numbers and Geometry) also become headlines in the long-term plans. Short-term planning includes analyzing tasks to see what mathematical ideas students will meet and also to make detailed descriptions of what to talk about and what examples to use in a whole-class presentation.

To make decisions about the mathematical content in the planning process, teachers reflect and have considerations in relation to students and their prior knowledge, which is expressed, for example, as: "[We had] a test with simple equations [...]. And that was because I wanted a starting point to know how to continue." Another teacher gives an example of how the planning fails due to lack of insights: "some things surprised me, for example locating points in a coordinate plane. Suddenly many students did not know how to do it, and everything was delayed." In this example, the teacher had misjudged students' prior knowledge and 
therefore chosen too difficult examples, which is an example of when plans are made based on expected scenarios and needs to be adjusted when meeting with the students.

Although it seems implied that planning is done in relation to specific students and groups of students, teachers sometimes use the same plans for several groups, expressed, for example: "now one group regulates the others." One teacher describes how "there are some things in common for all groups, and then there also is planning for each class or group," which also is an example of using the same planning as the starting point for several groups. However, plans made by others have to be adjusted by each teacher, partly because students and groups are different, but also because teachers choose to teach differently. When planning, teachers often think of a 'middle group' of students, which is visible in utterances such as "then some students already know this" and means that students in need of more challenges are overlooked.

Teachers value planning as beneficial for students' learning, which one teacher express as: "the biggest advantage is when you plan well. Then you have a chance to think things through, for example, which students you want to push." Planning also contributes to teachers' possibilities to see students' knowledge in the classroom: Well-planned lessons with clear aims make it easier to make assessments on the go, and, as one teacher says, "move around during the lesson and catch sight of what they [the students] know." Being well-planned is also a possibility to individualize teaching, e.g., to think through which students should answer which questions. Planning and assessment are thought of as tightly linked together, although time invested in planning is expressed as more valuable for students' learning than time invested in assessment.

Other issues that need reflection from teachers are the choice of activities and the division of mathematical content. One teacher expresses that some activities are chosen habitually instead of consciously reflecting on which activities best benefit students' learning. Another teacher said: "working so divided have the consequence when all parts are brought together, for example at national tests it is harder for the students," which indicate that dividing mathematical content in the same way textbooks do might have consequences for students' possibilities to deal with complex tasks. 
Resources for planning

When planning, teachers draw on different resources. Often mentioned in the interviews are textbooks and colleagues. Textbooks seem to frequently form the base for planning in various ways, including as a template for how to divide the mathematical content. Teachers seem to use textbooks differently based on how experienced they are, which one teacher express as: "Honestly, I have used the textbook so many years, so I do not have to make so much effort to know what parts to focus or what exercises students shall work with." Her story indicates that using the same textbook many years saves time in the planning process.

Although textbooks often are used as a base when planning, teachers often complement tasks in the textbook with activities that are in line with aims for the period. These activities can, for example, be found in other books or on the Internet, and often materials such as worksheets or cards with numbers or pictures have to be produced beforehand. One teacher problematizes this administrative work being part of the planning process: "it takes much time to laminate and make cards [...] it is expensive working time that we spend on making the material".

Another resource mentioned in the interviews is colleagues. Most work in the short-term planning seems to be done alone, while work in the long-term planning more often is done in collaboration, which one of the teachers expresses frustration with:

\footnotetext{
"When will I be able to plan with my colleagues? The work turns into working alone, although I don't want it. It is a lot... We make these big, long-term plans, but we never have time to see each other once we have started."
}

The quotation is an example of teachers thinking of planning as something that is preferably done in collaboration also in short-term planning.

\section{Work of planning}

Planning is seen as an essential part of teachers' work that has consequences for students learning as well as teachers' work situation - planning can cause stress as well as be a way to reduce stress. When planning, frames for teaching are made. However, these frames often need to be adjusted in the teaching situation, although modifications also can be made before meeting with the students, for example, when spontaneous ideas replace prior planning. 
The work of planning varies for several reasons; for example, what time of the school year the planning is done. At the beginning of a school year, teachers, as well as students, have more energy to be creative and put more effort into the planning so that they can plan for teaching that demands more of students. One teacher expresses the variation: "it depends on what time of the year it is if you have the energy or not." In semesters where national tests take place, planning seems to focus on repetition.

Students' age is another aspect that makes the work on planning vary. For example, teachers who meet younger students have to think about what more complex processes such as reasoning might be for the youngest students or think about how to translate aims and goals so that they are understandable for the students. Teachers who teach older students need to consider their right to participate in planning.

Decisions are made in advance and at the moment. Sometimes the decisions are hasty, and sometimes they are well thought through, and previous experiences are used to make them. Sometimes detailed plans are made at the moment, which one teacher calls spontaneous planning:

\begin{abstract}
"Spontaneous last-minute planning often turns out well [...], but you often dis it because it was spontaneous. Instead, you should take the time afterward and write down or memorize that this was good. I can use this in my planning another time".
\end{abstract}

The spontaneous planning might, according to the same teacher, be more influenced by students, and lead to valuable experiences, especially if reflections are made afterward.

\title{
Impact from others
}

Planning is influenced by the material as well as by people. For example, national curriculum influence planning and planning can be seen as a way to ensure that content from the national curriculum is covered. Another result pointing to influence on planning is that decisions made by other actors, such as school leaders, influence teachers' planning. Their organizational decisions have consequences for teachers' possibilities to, for example, plan for letting students work in smaller groups and work thematically in cooperation with other teachers. Their decisions also influence to what degree teachers can be creative. For example, requirements to plan in a specific template can change the process of planning from creative to instrumental, and from doing planning for yourself to doing it for others - written plans often should be available to school leaders and parents - and the purpose of that is sometimes 
perceived as a way to control teachers.

When planning, teachers seem to evaluate their thoughts on mathematics teaching and activities they want to do against the thoughts of others, and also against some general idea of what mathematics teaching is and how it should be done. One example of this is when one teacher wants to change her teaching and asks herself: "Do I dare? Do I have the energy [to argue for her choices with parents]?”

\subsection{Emotional aspects}

Emotional aspects seem to be a key to new insights about the meaning of planning in mathematics teaching; they emerge on several levels and span the aspects presented above. Planning itself raises feelings explicitly expressed by the teachers. In addition, feelings are also implicitly expressed, for example, when describing imagined or real consequences of decisions made in the planning process, or as consequences of decisions made by others that influence the planning. There is a multitude of feelings that emerge: joy, creativity, shame, and control are some examples.

When teachers say: "It is a freedom to feel that I can do differently with different students" and "I have been at schools where teachers are trusted [to plan and organize their teaching by themselves]," they express feelings of freedom and trust. These feelings were emphasized as important, and part of the joy teachers feel when planning.

In contrast to freedom, there are examples of teachers feeling constrained in the process of planning, expressed by one teacher who has been obliged to use a specific template for planning:

"I have had exactly that content, but it has not been as formal. That formality... Everything must look the same. That makes me feel locked in, or I feel that I am not as free in my thinking as before."

In this quotation, the teacher turns against the template and talks about her decrease in creativity. In another part of the interview, the same teacher emphasizes creativity as necessary for planning fruitful mathematics teaching. Creativity, which in the interviews is talked about as related to feelings, is also raised by another teacher when she refers to administrative work and says that this "takes away a lot of the creativity [in planning process]" which made her feel more constrained and planning became more boring. Hence, creativity seems to be related to joy, which is prominent in the example when one teacher says: "The fun part is to think about how to explain this in 
the best way." Fun is a term that also comes up in utterances as: "Planning in mathematics is really fun," where the teacher describes a feeling of joy related to this specific part of the work, especially when it is done in cooperation with other teachers.

Planning can also raise frustration: "Neither the students nor I get the help we need" That makes me angry, and then I get... [teacher cries]". In this situation, the teacher describes how she thinks it is impossible to do the planning she wants due to a lack of resources. She has to plan and organize her teaching in ways she knows will not benefit students' learning. Her expression of anger and sadness seems to reveal a feeling that both she and her students are abandoned.

Feelings of insecurity also emerge in the interviews. One teacher expresses it as "a fear that I will go to low" which indicates that the teacher is worried about not being able to challenge all students, or as when a teacher talks about how she has planned her teaching without textbooks for some time: "I have always been afraid not to have a textbook." In the first example, insecurity is related to students, not giving them what they need, and the second example is insecurity related to the teacher herself, a textbook is safe - without it, the teacher has to rely on herself. Common for expressions of insecurity is that teachers worry about not planning a mathematics teaching that benefits students' learning optimally and also is accepted by students, parents, and other actors.

Another example relating to other actors is the teacher who refers to herself as "bounded to textbooks" and express how they make her feel safe, although she "knows that it [being bounded to textbooks] does not sound good." Here she expresses that other actors have opinions and implies a feeling of shame for relying on the textbooks in her planning. Shame is also present in an example where one teacher describes how she met students' desires and changed her teaching. In the interview, she recalls a conversation with her students: "I am getting a little embarrassed because this is not what I stand for. So, there are tensions. You know, now I am as old-fashioned as I was before. Five years ago." In this quotation, she implies that abandoning her ideas about mathematics teaching and organizing her teaching in line with students' desires makes her feel ashamed since she does not teach the way she wants to.

Feelings related to students are common when planning. Thinking of how to explain a specific content to students is described as fun, while feelings of insufficiency or sadness are visible, for example, when one teacher talked about a test situation: "It was a fiasco. I felt despair [...], and I just felt that I had turned myself inside out. I didn't know what to do!" In this situation, the teacher did not know how to plan her 
teaching to give students opportunities to learn, which seems to cause a feeling of powerlessness.

\section{Discussion and conclusions}

Results from this study indicate that meaning Swedish teachers ascribe to planning in many respects are in line with the previous research from other contexts presented earlier in the article, for example, that planning is done in long-term and short-term, that textbooks are frequently used, and that colleagues are seen as resources. Hence, it seems as although planning is a cultural, contextual phenomenon; there are similarities so that conclusions drawn in one context might be valuable for other contexts as well. This means that findings from this Swedish context in this study, which reveal planning for mathematics teaching as an even more complex process than previously shown, might be worth taking into consideration also in other contexts. This study contributes with new insights by showing that others' opinions and ideas highly influence teachers' planning, both when it comes to how the planning is done and when it comes to the mathematics teaching planned for. This study also shows how feelings are important, but previously often neglected, part of the planning for mathematics teaching.

Planning for mathematics teaching gives rise to a series of feelings, such as joy and shame. Feelings of joy are expressed in relation to being creative in the planning process. These results can be compared to research showing that one way to implement reforms and to support teachers in the planning process is to make teacher guides with detailed instructions (e.g., Superfine, 2008). Such teacher guides might correspond with indications that teachers need support in extracting important mathematical ideas (Sullivan et al., 2013). However, the results in this study indicate that there might be a risk that such teacher guides reduce creative work and, consequently, also the joy with planning, which might have unwanted consequences.

Another recurring theme in the interviews that influences teachers' work is templates and models for planning. Previous research indicates that templates and models are not used by in-service teachers but frequently used in teacher education (Zazkis et al., 2009). However, findings in this study indicate that some teachers are obliged to use templates, which affects their planning as well as their feelings concerning planning negatively. Whether the purpose is to facilitate planning or to, as John (2006) suggests, control teachers, making templates mandatory might, as findings from this study indicate, have negative consequences. Hence, initiatives 
intended to support teachers' planning processes may not automatically do so, and more information is needed about how supportive initiatives should be designed to contribute in a fruitful way to teachers' planning and ultimately to students' learning.

Several examples in previous research emphasize planning as a task for the teacher without acknowledging that the teacher does the planning in social settings influenced by values, opinions, and decisions from others. Although some studies (e.g., Gómez, 2002; Sullivan et al., 2013) widen the view and recognize planning as a social activity that can be made with colleagues, research most often positions the teacher as someone who can make decisions regarding teaching independently. Teachers as independent and free to plan their teaching as they want to correspond well with writing that preceded the Swedish national curriculum (Utbildningsdepartementet, 2009). However, results from this study show that planning is situated and influenced by opinions, ideas, and decisions from others, which means that even if teachers are the ones responsible for planning, planning is not something teachers can do in isolation from context, from governing, and from other actors, such as colleagues, school-leaders, students, and parents. Hence, teachers, as independent actors in the planning process, can be questioned.

Feelings of shame are expressed when teachers make decisions and organize teaching in a way that is not consistent with their own ideas about how mathematics teaching should be done. It seems like some teachers refer to an unspoken common idea about how mathematics teaching should be done, an idea that students, parents, school leaders, and others can hold against them if they teach in another way. Hence, teachers sometimes act against their own ideas to teach in line with the ideas of others. This means that not only teachers' traditions, expectations, and assumptions are of importance when planning in mathematics teaching, but also several other actors. Hence, it is not enough that teachers are well-educated and informed about how to organize teaching to support students' learning if there are other actors with different views of good mathematics teaching that have the power to influence decisions on teaching.

How decision-makers at an organizational level look at planning and mathematics teaching also have consequences for teachers' planning, for example, if teachers have allocated time with their colleagues, how long lessons are and when they are scheduled, and if school leaders have opinions about what and how the teacher teaches. 
Results from this study build on interviews with six teachers, and hence, it is not possible to generalize findings to what meaning all teachers ascribe to planning. Nevertheless, findings give insights into some teachers' meaning and thereby contribute with new insights about the complexity of being a teacher and also shed light on the gap between what meaning teachers ascribe to planning and the ways decision-makers may deal with planning in mathematics teaching. Feelings as an important part of planning in mathematics raise questions about what lies behind them and what can be done for the positive feelings to outweigh, at the same time as planning is done so that the students are given the best opportunities to learn mathematics. The results might also be of value for teachers who, by reflecting on a specific part of their work that they may often take for granted, may come to new insights that benefit them in their professional practice. For example, being aware of that the views of other actors, such as school-leaders, influence the planning, might open up for discussions between teachers and school leaders about what mathematics teaching should be. In addition, results need to be considered in discussions about how to support teachers and student teachers in their planning, so that initiatives, on the one hand, are based on what teachers already do, and on the other hand, function as a way to make research in mathematics education influence the planning of and thus the teaching of mathematics.

\section{References}

Alvesson, M., \& Karreman, D. (2000). Varieties of discourse: On the study of organizations through discourse analysis. Human Relations, 53(9), 1125-1149. doi:10.1177/0018726700539002

Braun, V., \& Clarke, V. (2006). Using thematic analysis in psychology. Qualitative Research in Psychology, 3(2), 77-101. doi:10.1191/1478088706qpo630a

Cherryholmes, C. H. (1999). Reading pragmatism. New York, NY: Teachers College Press.

Clark, C. M., \& Yinger, R. J. (1987). Teacher planning. In J. Calderhead (Ed.), Exploring teachers' thinking (pp. 84-103). London, England: Cassell Educational.

Clarke, D. J., Clarke, D. M., \& Sullivan, P. (2012). How do mathematics teachers decide what to teach? Australian Primary Mathematics Classroom, 17(3), 9-12.

Evans, J. (2001). Developing the ideas of affect and emotion among adult learners. In L. Östergaard Johansen \& T. Wedege (Eds.), Numeracy for Empowerment and Democracy? Proceedings of the $8^{\text {th }}$ International Conference of Adults Learning Mathematics (ALM8) (pp. 88-96). Roskilde, Denmark: Roskilde University.

Fairclough, N. (2003). Analyzing discourse: textual analysis for social research. New York, NY: Routledge.

Fairclough, N. (2016). A dialectical-relational approach to critical discourse analysis in social research. In R. Wodak \& M. Meyer (Eds.), Methods of critical discourse studies ( $3^{\text {rd }}$ ed., pp. 86-108). Los Angeles, CA: Sage. 
Gómez, P. (2002). Theory and practice in pre-service mathematics teacher education from a social perspective. In P. Valero \& O. Skovsmose (Eds.), Proceedings of the 3rd International MES Conference (pp. 1-13). Copenhagen: Centre for Research in Learning Mathematics.

Hargreaves, A. (1998). The emotional practice of teaching. Teaching and Teacher Education, 14(8), 835-854. doi:10.1016/So742-051X(98)00025-0

John, P. D. (2006). Lesson planning and the student teacher: re-thinking the dominant model. Journal of Curriculum Studies, 38(4), 483-498. doi:10.1080/00220270500363620

Martin, D. B., \& Mironchuk, A. (2010). Plan B: If I knew then what I know now. New England Mathematics Journal, 42, 20-29.

Meaning. (n.d.). In Cambridge Dictionary. Retrieved from https://dictionary.cambridge.org/dictionary/english/meaning

Muñoz-Catalán, C. M., Yánez, J. C., \& Rodríguez, N. C. (2010). Mathematics teacher change in a collaborative environment: to what extent and how. Journal of Mathematics Teacher Education, 13, 425-439. doi:10.1007/s10857-010-9157-5

Potari, D., Figueiras, L., Mosvold, R., Sakonidis, C., \& Skott, J. (2015). Introduction to the papers of TWG19: Mathematics teacher and classroom practices. In K. Krainer \& N. Vondrová (Eds.), Proceedings of the Ninth Conference of the European Society for Research in Mathematics Education (CERME9, 4-8 February 2015) (pp. 2968-2973). Prague, Czech Republic: Charles Univeristy in Prague, Faculty of Education and ERME.

Qu, S. Q., \& Dumay, J. (2011). The qualitative research interview. Qualitative research in accounting \& management, 8(3), 238-264. doi:10.1108/11766091111162070

Quennerstedt, M., Öhman, J., \& Öhman, M. (2011). Investing learning in physical education - a transactional approach. Sport, Education and Society, 16(2), 159-177.

Remillard, J. T. (2005). Examining key concepts in research on teachers' use of mathematics curricula. Review of Educational Research, 75(2), 211-246. doi:10.3102/00346543075002211

Remillard, J.T., Herbel-Eisenmann, B., \& Lloyd, G.M. (Eds.). (2009). Mathematics teachers at work: Connecting curriculum materials and mathematics instruction. New York, NY: Routledge.

Roche, A., Clarke, D. M., Clarke, D. J., \& Sullivan, P. (2014). Primary teachers' written plans in mathematics and their perceptions of essential elements of these. Mathematics Education Research Journal, 26, 853-870. doi:10.1007/s13394-014-0130-y

Skott, J., Mosvold, R., \& Sakonidis, C. (2018). Classroom practice and teachers' knowledge, beliefs, and identity. In T. Dreyfus, M. Artigue, D. Potari, S. Prediger, \& K. Ruthven (Eds.), Developing research in mathematics education. Twenty years of communication, cooperation and collaboration in Europe (pp. 162-180). Oxon, UK: Routledge.

Sullivan, P., Clarke, D., Clarke D., Gould, P., Leigh-Lancaster, D., \& Lewis, G. (2012). Insights into ways that teachers plan their mathematics teaching. In J. Dindyal, L. P. Cheng, \& S. F. Ng (Eds.), Mathematics education: Expanding horizons. Proceedings of the $35^{\text {th }}$ annual conference of the Mathematics Education Research Group of Australasia (pp. 696-703). Singapore: MERGA, Inc.

Sullivan, P., Clarke, D. M., Clarke, D. J. Farrell, L., \& Gerrard, J. (2013). Processes and priorities in planning mathematics teaching. Mathematics Education Research Journal, 25, 457-480. doi:10.1007/s13394-012-0066-Z

Superfine, A. C. (2008). Planning for mathematics instruction: A model of experienced teachers' planning process in the context of a reform mathematics curriculum. The Mathematics Educator, 18(2), 11-22.

Superfine, A. C. (2009). The "problem" of experience in mathematics teaching. School Science and Mathematics, 109(1), 7-19. doi:10.1111/j.1949-8594.2009.tb17858.x 
Utbildningsdepartementet. (2009). Uppdrag att utarbeta nya kursplaner och kunskapskrav för grundskolan och motsvarande skolformer m.m. (U2009/312/S). Retrieved from https://www.regeringen.se/49b714/contentassets/25958d8de58541efagd46cd8d104da6e/ uppdrag-att-utarbeta-nya-kursplaner-och-kunskapskrav-for-grundskolan-ochmotsvarande-skolformer-m.m

Zazkis, R., Liljedahl, P., \& Sinclair, N. (2009). Lesson plays: Planning teaching versus teaching planning. For the Learning of Mathematics, 29(1), 40-47.

Zembylas, M. (2005). Teaching with emotion. Greenwich, CT: Information Age Publishing.

Zembylas, M. (2007). Theory and methodology in researching emotions in education. International Journal of Research \& Method in Education, 30(1), 57-72. doi:10.1080/17437270701207785 